\title{
Making Our Roads Safer for the Citizens of India
}

\author{
Amrita Ghosh ${ }^{1} \quad$ Ranabir Pal ${ }^{2}$ Luis Rafael Moscote-Salazar ${ }^{3} \quad$ Amit Agrawal $^{4}$
}

\author{
${ }^{1}$ Department of Biochemistry, Calcutta Medical College, Kolkata, \\ West Bengal, India \\ 2Department of Community Medicine, Mata Gujari Memorial \\ Medical College and LSK Hospital, Kishanganj, Bihar, India \\ ${ }^{3}$ Neurosurgery-Critical Care, Red Latino, Organizacion \\ Latinoamericana de Trauma y cuidado, Neurointensivo, Bogota, \\ Colombia \\ ${ }^{4}$ Department of Neurosurgery, All India Institute of Medical \\ Sciences, Saket Nagar, Bhopal, Madhya Pradesh, India
}

Indian J Neurotrauma:2021;18:84-85

Road traffic injuries (RTIs) are estimated to constitute onefourths of global disability adjusted life year (DALY) loss and are going to become the third top causes of DALY loss by 2020 from the existing ninth place. ${ }^{1}$ Road safety is a vital paradigm of quality of life to bring holistic socioeconomic and logistical paybacks to global health. ${ }^{1}$ Despite RTIs being predictable and to a large extent preventable, global road safety agenda was out of vision for long times., ${ }^{2,3}$ The speedy growth and development of the road linkages in India with the increase in number of motorized vehicles have led to a considerable escalation in intensities, quantities, magnitude, and expansion, on a countrywide scale, of commuter and cargo movements. The mainstay of the research on the RTI is an injury registry with special emphasis on traumatic brain injury to bridge the lacunae of information on risk factors, interventions, and outcomes in the developed world. ${ }^{4}$

We need a representative national database to assess the health impact of injury with a range of socioeconomic downstream effects. The developed countries have improved their quality of care of the injury at hospital and pre-hospital levels by using injury registry, which is a cost-effective yet comprehensive data-collection system that includes assorted parameters of probable interventions in any scenario. In spite of highest sincerity, as the trauma registry is a hospital-based data collection system, it may not give information about pre-hospital care. ${ }^{3.5}$ In the holistic concept of road safety, we need to internalize that life is indeed a learning process; no matter whatever titles or positions we hold or have had under our belts or how old we are, we need to experience and learn about that we may have limited ability in the course of everyday living. We need extensive capacity building of community-level injury intervention at all levels of curricular health care teaching learning on priority. ${ }^{6,7}$

Road safety is a shared responsibility among numerous stakeholders; as such, all should work hand in hand toward

published online

August 26, 2020
DOI https://doi.org/

10.1055/s-0040-1713325

ISSN 0973-0508.
Address for correspondence Amit Agrawal, MCh, Department of Neurosurgery, All India Institute of Medical Sciences, Saket Nagar, Bhopal 462020, Madhya Pradesh, India (e-mail: dramitagrawal@gmail.com).

one goal of road safety. ${ }^{8}$ Well-planned pre-hospital care training needs to be harnessed at all levels, starting from the first responder training to improving infrastructure, and all the logistics to upgrade. Further, there is need for updating of the capacity building of first responders, namely police, fire brigade, and ambulance personnel, so that they can confidently perform the airway, breathing, circulation, disability, and exposure (ABCDE) scrutiny, resuscitate, triage, etc., instead of adopting the "scoop and run" policy as conventionally practiced. The bystanders at the injury site play a crucial role-when each moment is invaluable to save the life from danger-by providing $\mathrm{ABCDE}$ approach that is easy to learn. ${ }^{9}$ We need to understand road safety beyond the compulsory use of protective gears. We have to set up a platform for evaluating the gaps in intervening RTIs. Further, we need to synthesize the results and extrapolate the findings from global road safety research and administrative footsteps to save citizens of our country.

\section{Conflict of Interest}

None declared.

\section{References}

1 Pal R, Ghosh A, Kumar R, et al. Public health crisis of road traffic accidents in India: risk factor assessment and recommendations on prevention on the behalf of the Academy of Family Physicians of India. J Family Med Prim Care 2019;8(3):775-783

2 Agrawal A, Kakani A, Baisakhiya N, Galwankar S, Dwivedi S, Pal R. Developing traumatic brain injury data bank: prospective study to understand the pattern of documentation and presentation. Indian J Neurotrauma. 2012;9(2):87-92

3 Agrawal A, Munivenkatappa A, Shukla DP, et al. Traumatic brain injury related research in India: an overview of published literature. Int J Crit Illn Inj Sci 2016;6(2):65-69

4 Agrawal D. Trauma systems and services in India. Indian J Neurotrauma 2019;16(02/03):075 
5 Pal R, Munivenkatappa A, Agrawal A, et al. Predicting outcome in traumatic brain injury: sharing experience of pilot traumatic brain injury registry. Int J Crit Illn Inj Sci 2016;6(3): 127-132

6 Bharati D, Nandi P, Pal R, Yamuna T, Lokeshmaran A, Sarker G. Evaluation of retention of knowledge and skills imparted to third semester MBBS students through basic prehospital care of fracture. Trop J Med Res 2016;19(2):118-123
7 Pal R, Kumar R, Pal S. Vidyasagar, Mukherji B, Debabrata S Medical education: the hot seat. J Family Med Prim Care 2016;5(1):20-23

8 Pal R. Injury epidemiology: The neglected chapter. J Epidemiol 2012;2(4):216-218

9 Vyas D, Hollis M, Abraham R, et al. Prehospital care training in a rapidly developing economy: a multi-institutional study. J Surg Res 2016;203(1):22-27 